\title{
Randomised comparison of procedures for obtaining informed consent in clinical trials of treatment for cancer
}

\author{
R J SIMES, M H N TATTERSALL, A S COATES, D RAGHAVAN, H J SOLOMON, \\ H SMARTT
}

\begin{abstract}
Methods of obtaining informed consent have evolved differently in Western countries without substantive information on the impact of these different practices on the patients. A randomised study was performed to compare two commonly adopted methods of seeking consent to randomised treatment: an individual approach at the discretion of each doctor and a uniform policy of total disclosure of all relevant information. The impact of both consent procedures on the patient's understanding and anxiety levels and on the doctor-patient relationship was assessed by means of a questionnaire given soon after the consent interview. Fifty seven patients were assigned at random to two groups: to 29 patients an individual approach to seeking consent was adopted and to 28 patients all relevant information was given. Seven patients refused consent to randomised treatment, with slightly more refusals by patients in the total disclosure group ( $5 \vee 2, \mathbf{p}=0.25)$. The main effects of total disclosure of all information compared with an individual approach to seeking consent were: a better understanding of treatment and side effects and of research aspects of the treatments; less willingness to agree to randomised treatment; and increased anxiety. No significant differences were found in patients' perceptions of the doctor-patient relationship. A repeat questionnaire given three to four weeks later no longer showed significant differences between the two groups.
\end{abstract}

\section{Introduction}

When seeking consent from patients to participate in clinical trials the amount and kind of information they should be given is the subject of considerable debate, especially when the trials are randomised and entail the treatment of cancer. ${ }^{1 \cdot-7}$

For clinical trials comparing randomised treatments countries such as the United Kingdom and Australia have allowed considerable latitude in what the patient is told. This is not so in the United States, where federal regulations require doctors taking part in trials to obtain fully informed consent from their patients, with rigid adherence to a procedure for obtaining comprehensive and written informed consent. ${ }^{8}$ The possibility of change in the United Kingdom and Australia towards a policy similar to that in the United States has caused some concern that this may not be in the

\footnotetext{
Ludwig Institute for Cancer Research (Sydney Branch), Blackburn Building University of Sydney, and the Centenary Institute for Cancer Medicine and Cell Biology, Sydney, New South Wales 2006, and Royal Prince Alfred Hospital, Camperdown, New South Wales 2006, Australia

R J SIMES, SM, FRACP, medical oncologist

M H N TATTERSALL, MD, FRACP, professor of cancer medicin

A S COATES, MD, FRACP, associate professor of cancer medicine

D RAGHAVAN, PHD, FRACP, medical oncologist

H J SOLOMON, FRACOG, gynaecological oncologist

H SMARTT, FRANZCP, psychiatrist
}

Correspondence to: Dr R J Simes, Ludwig Institute for Cancer Research, Blackburn Building, University of Sydney, Sydney, New South Wales 2006, Australia. best interest of the patients, ${ }^{26}$ while others have argued that such a change is long overdue.

Some people fear that a policy of fully informed consent based on the model in the United States may cause increased confusion rather than increased understanding among patients ${ }^{69}$ and that it may lead to considerable anxiety. ${ }^{2}$ Furthermore, the need to disclose the method of selecting treatment (randomised) and other research aspects of the trial might undermine patients' confidence and a positive doctor-patient relationship. ${ }^{111}$ Concern has also been expressed that regulations focus more on the amount of information disclosed than on the quality of communication between doctor and patient. ${ }^{12}$

Against these potential harmful effects must be balanced the need to respect each patient's autonomy and to allow patients to play an active part in medical decisions about their future. ${ }^{713.15}$ Furthermore, some people have argued that failing to disclose information may cause unnecessary anxiety because patients may think that they are being kept in the dark ${ }^{216}$ and that the doctor-patient relationship must always be based on full and frank discussions. ${ }^{4}$

There is little objective information on the possible consequences for patients of different approaches to seeking consent. We therefore undertook a prospective randomised study comparing two methods of obtaining consent for randomised clinical trials of treatment for cancer: $(a)$ an individual approach, where the amount of information given to the patient was left to the discretion of each doctor and consent was verbal; and $(b)$ a uniform policy of total disclosure of all information relevant to the clinical trial, both verbally and in a written consent form.

The major end points of the study were the effects of the two consent procedures on patients' willingness to participate in clinical trials, on their understanding of their illness and treatment, on their anxiety levels, and on their perception of the doctor-patient relationship.

\section{Patients and methods}

PATIENTS

Patients who were candidates for any one of 16 randomised clinical trials being undertaken at the oncology unit of the Royal Prince Alfred Hospital, Sydney, were eligible for the study. Patients were included in the study only if they were aged 18 to 75 years, were able to speak English, and could have their treatment safely delayed by at least 24 hours. Before entering the study the patients agreed to answer a questionnaire about their illness and treatment. Approval to conduct the study was obtained from all referring consultants and the hospital ethics committee.

\section{EXPERIMENTAL DESIGN}

The figure shows the basic design of the consent study. Patients were first stratified on the basis of age and type of randomised clinical trial for which consent was sought: trials comparing treatment with no treatment; trials comparing dissimilar treatments; and trials comparing similar treatments. The type of consent procedure was then allocated by sealed envelopes using a form of balanced randomisation. ${ }^{17}$

The topics covered during the consent interview by the consultant were recorded at the time by a third person (oncology registrar) whenever possible and otherwise by the main interviewer immediately after the interview. If consent was obtained the patient was then assigned at random to receive treatment in the relevant clinical trial; otherwise the patient was treated outside the trial. In either case patients were asked to complete a questionnaire both before receiving treatment and three to four weeks later. 


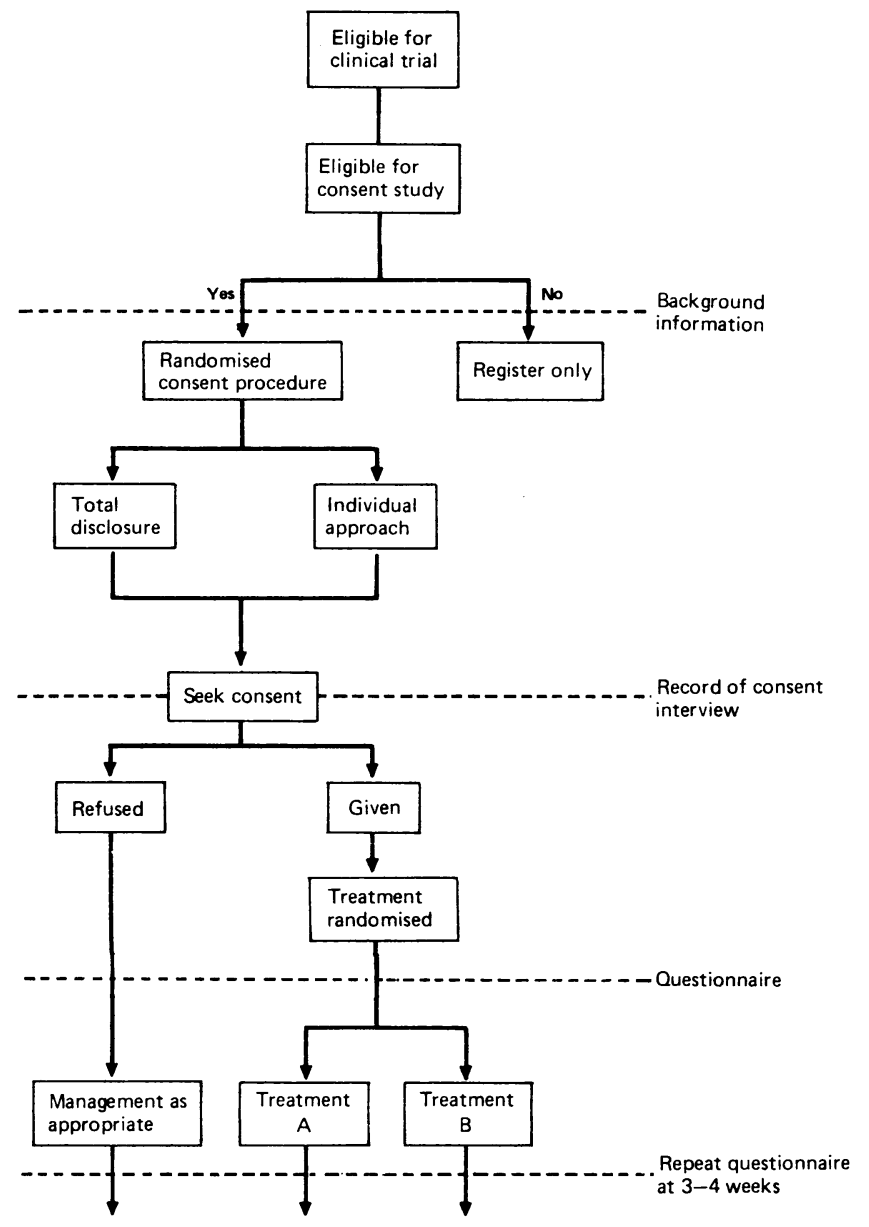

Design of the informed consent study.

\section{CONSENT PROCEDURES}

Individual approach-All patients were given information about the aims, expected results, and potential toxicities of treatment. Details of treatment, however, were left to the discretion of each consultant. All patients were given the opportunity to ask further questions, after which verbal consent was obtained.

Total disclosure-All patients were fully informed by the consultant: $(a)$ that they had cancer; $(b)$ of the aims of treatment and the chance of success; (c) that treatment was part of a research study; $(d)$ that treatment was allocated randomly; $(e)$ of appropriate alternative treatments; $(f)$ of all possible side effects of treatment; $(g)$ that they were free to withdraw from the study and still receive treatment if desired; and $(h)$ that they had the opportunity to ask further questions. In addition, each patient was given a consent form outlining this information. ${ }^{\star}$ The consent form was kept overnight and written consent was obtained the next day.

\section{ASSESSMENT OF PATIENTS}

Each patient completed a questionnaire ${ }^{\star}$ which contained questions designed and pretested specifically for this study. Patients also completed the Spielberger questionnaire for assessing anxiety state. ${ }^{18}$ Questions covered patients' attitudes to the information received, their confidence, and their perceptions of the doctor-patient relationship. They also tested patients' knowledge of diagnosis, aims of treatment, possible side effects, alternative treatments, and research aspects of the proposed treatment plan.

Responses to most questions were assigned a score on a five point scale. Three measures of the doctor-patient relationship were calculated from linear combinations of prespecified sets of questions. These measures, determined a priori, were labelled: $(a)$ patient's confidence in doctors; $(b)$ personal doctor-patient relationship; and $(c)$ treatment decided on an individual basis.

A measure of each patient's willingness to participate in the study as a result of the consent interview was based on whether the patient consented to randomised treatment and on the answer to the following question: "What

* Copies of questionnaire and consent forms may be obtained from the authors on request. effect has the information you have received had on your decision about agreeing to treatment?: Made it much easier to agree, easier to agree, no difference, harder to agree, decide not to agree." Patients refusing consent were automatically coded as "decide not to agree."

Two measures of the patient's knowledge were calculated: $(a)$ knowledge of diagnosis, treatment, and possible side effects; and $(b)$ knowledge of research aspects of the trial in which the patient was being asked to participate. The information contained in the relevant consent form and given during the consent interview was used to judge the correct responses in each case. The patient's anxiety level was determined using the standard method for the Spielberger questionnaire. ${ }^{18}$ Thus there were seven major outcomes: willingness to participate; confidence in doctors; personal doctorpatient relationship; individual treatment; knowledge of treatment and side effects; knowledge of research aspects; and anxiety level.

\section{STATISTICAL METHODS}

The impact of the two consent procedures on the major outcomes was assessed using individual $t$ tests, provided an overall test on these outcomes (Hotelling's $\mathrm{T}^{219}$ ) was significant. The impact of covariates, such as patients' characteristics and type of trial, on these conclusions was assessed using multivariate analysis of variance. ${ }^{19}$ Categorical data were analysed using rxc exact tests. ${ }^{20}$ All tests were two sided.

\section{Results}

The study covered the period June 1981 to April 1984 and included 57 patients. The original plan was to include 100 patients, but the study ended early because of declining numbers when several of the randomised clinical trials closed. An additional 74 patients eligible for one of the randomised clinical trials were not included in this study for reasons which included inability to delay treatment by 24 hours (37), language difficulty (14), logistical difficulties (11), refusal by the patient (6), and emotional or mental problems (4).

\section{CHARACTERISTICS OF PATIENTS}

Table I shows the demographic and medical characteristics of the patients. The type of clinical trial for which consent was sought varied considerably, covering 13 different randomised studies. The groups were well balanced on this variable, however, and there were no significant differences in any of the patients' characteristics by consent procedure.

TABLE I-Demographic and medical characteristics of patients. Values are numbers of patients, except for age

\begin{tabular}{lcc}
\hline & \multicolumn{2}{c}{ Consent procedures } \\
\cline { 2 - 3 } & $\begin{array}{c}\text { Individual approach } \\
(\mathbf{n}=29)\end{array}$ & $\begin{array}{c}\text { Total disclosure } \\
(\mathbf{n}=28)\end{array}$ \\
\hline Median age (years) & 55 & 56 \\
Age range (years) & $40-74$ & $31-68$ \\
No of women & 18 & 23 \\
No of white patients & 29 & 27 \\
Educational standard high school or below & 21 & 20 \\
No of married patients & 19 & 22 \\
English as first language & 27 & 26 \\
Initial ECOG* performance state: & 20 & 18 \\
$\quad 0$ & 9 & 10 \\
1-3 & 9 & 9 \\
Malignancy: & 5 & 7 \\
$\quad$ Ovary & 4 & 3 \\
Breast & 3 & 3 \\
Head and neck & 5 & 1 \\
Gastric & 1 & 4 \\
Small cell lung & 1 & 1 \\
Unknown primary & 1 & 0 \\
Colorectal & & \\
Bladder & & \\
\hline
\end{tabular}

^Eastern Cooperative Oncology Group.

\section{CONSENT INTERVIEW}

Four doctors undertook most $(93 \%)$ of the consent interviews. Table II shows the subjects covered by the doctor during the interview. The tota disclosure interview did not always cover all areas verbally as required by the protocol, but all patients in this group received this information on the

(1)

.

(1)


TABLE II-Subjects covered during the consent interview. Results are numbers of patients for whom each subject was covered

\begin{tabular}{lcc}
\hline & \multicolumn{2}{c}{ Consent procedures } \\
\cline { 2 - 3 } Subjects covered & $\begin{array}{c}\text { Individual approach } \\
(\mathbf{n}=28)^{\star}\end{array}$ & $\begin{array}{c}\text { Total disclosure } \\
(\mathbf{n}=28)\end{array}$ \\
\hline Diagnosis & 27 & 28 \\
Prognosis & 22 & 28 \\
Part of research study & 20 & 28 \\
Randomisation explained & 19 & 27 \\
Details of treatment in depth & 24 & 23 \\
Alternatives to treatment & 16 & 23 \\
Right to withdraw from treatment & 15 & 23 \\
Right to withdraw from study & 17 & 27 \\
Opportunity to ask questions & 28 & $12 \cdot 3(0 \cdot 8)$ \\
Side effects (mean (SE)) & $7 \cdot 2(0 \cdot 8)$ & $14 \cdot 2(0 \cdot 7)$ \\
Number mentioned & $13 \cdot 9(0 \cdot 6)$ & $86(4)$ \\
Number possiblet & $54(6)$ & \\
Percentage mentioned $\neq$ & &
\end{tabular}

*One consent interview was not recorded.

†Defined by side effects listed on relevant consent form.

$\ddagger$ Proportion of side effects mentioned as percentage of number possible.

TABLE III-Major outcomes of informed consent trial on initial questionnaire. Scores are standardised as a percentage (possible range 0-100) except anxiety scores (possible range 20-80). Each result is expressed as mean ( $S E$

\begin{tabular}{lccc}
\hline & \multicolumn{2}{c}{ Consent procedure } & \\
\cline { 2 - 3 } & $\begin{array}{c}\text { Individual } \\
\text { approach } \\
(\mathrm{n}=29)\end{array}$ & $\begin{array}{c}\text { Total } \\
\text { disclosure } \\
(\mathrm{n}=26)\end{array}$ & p value \\
\hline Outcome & $88(3)$ & $65(7)$ & $0 \cdot 01$ \\
Willingness to participate & $73(3)$ & $73(3)$ & $0 \cdot 90$ \\
Confidence & $76(2)$ & $77(3)$ & $0 \cdot 87$ \\
Personal doctor-patient relationship & $71(3)$ & $66(3)$ & $0 \cdot 17$ \\
Individualised treatment & $56(3)$ & $82(4)$ & $0 \cdot 0001$ \\
Knowledge of treatment and side effects & $59(4)$ & $73(5)$ & 0.03 \\
Knowledge of research aspects & $42(2)$ & $49(2)$ & 0.02 \\
Anxiety & & & 0.0001 \\
All outcomes & & & \\
\hline
\end{tabular}

consent form. The amount of information given by the two approaches was similar for diagnosis and details of treatment, but patients in the individual approach group were told less about uncommon side effects and about the research nature of the treatment.

While major differences between the consent procedures were due to the content of what patients were told, minor stylistic differences may also have occurred. Each doctor attempted to be just as approachable using either procedure and had indicated in a questionnaire before the consent study an open mind on the preferred approach to seeking consent.

\section{INITIAL QUESTIONNAIRE}

Two patients, both in the total disclosure group, failed to answer the initial questionnaire (one refused and one was considered too ill). The remaining 55 patients were included in the analysis of major outcomes (table III). Overall, there was a significant difference between the two groups ( $p=$ 0.0001 ). Patients in the total disclosure group were more knowledgeable about their illness and treatment $(\mathrm{p}=0.0001)$ and also about research aspects $(p=0.03)$. They were less willing, however, to participate in their chemotherapy trial as a result of the information they had received $(p=0.01)$ and were more anxious as judged by the Spielberger questionnaire $(p=0.02)$. The patient's perception of the doctor-patient relationship was similar in the two groups. Analysis of these major outcomes, after adjusting for patients' characteristics, type of trial, and main interviewer seeking consent, led to similar conclusions.

The main areas in which patients in the total disclosure group were more knowledgeable were side effects of treatment, the research nature of the study, and the method of selecting treatment. Of particular interest was the fact that more patients in the total disclosure group understood their treatment was selected by randomisation (11 $v 2 ; \mathrm{p}=0.004)$. Nevertheless, more than half of the patients in each group who were told about randomisation failed to understand this.

\section{REPEAT QUESTIONNAIRE}

Forty four patients $(80 \%)$ completed the same questionnaire again three to four weeks after the initial assessment. At this time the consent procedure no longer had any significant effect on the major outcomes $(p=0.48)$.

\section{REFUSAL TO CONSENT TO TREATMENT}

Seven patients did not consent to randomised treatment: two $(7 \%)$ of the 29 patients who had received an individual approach to consent refused compared with five (18\%) of the 28 patients in the total disclosure group $(p=0.25)$. This study had a low power $(55 \%)$ to detect a true difference of this magnitude. Patients who refused consent expressed less confidence in their doctors $(p=0.05)$ and did not consider that treatment was decided on on as much of an individual basis $(\mathrm{p}=0.05)$.

\section{Discussion}

The present study was conceived in 1980 at a time when Australian attitudes to consent were moving towards the American model. This trend has continued, and the National Health and Medical Research Council (Australia) now requires written consent for studies it supports. We would not be able to launch this study now because of these changes, which may also have contributed to the declining numbers of patients recruited during the latter phase of this study.

The evolution of a dogma of informed consent in clinical trials, initially in the United States and recently in Australia, has occurred largely in the absence of objective information on the impact on patients of different approaches to seeking consent. Our study provides this kind of information, and we believe that our results, discussed below, will help to provide a cost-benefit framework in which informed consent practices can evolve.

Patients' understanding of both treatment and research aspects of the trial were significantly better in the total disclosure group than among those receiving an individual approach to consent. Other studies have found that detailed written information alone probably does little to improve patients' understanding, ${ }^{2122}$ although some benefit may ensue if patients are allowed to take the written information home before giving consent. ${ }^{23}$ In our study detailed information was provided verbally in the interview as well as on the consent form, which was kept overnight for discussion with friends or relatives.

Significantly more patients in the total disclosure group understood that their treatment was selected by randomisation. But even when patients were given an explicit explanation of randomisation more than half still failed to understand. Whether it is necessary to disclose the fact of randomisation to all patients is an area of special controversy. If the way in which treatment is selected is material to the patient's decision to participate in the trial then such information should be given to the patient. ${ }^{7}$ However, this particular issue is also at the heart of the reluctance of many doctors to include their patients in clinical trials ${ }^{10}$ and has been a prime reason for seeking alternative designs to the classic randomised clinical trial. ${ }^{24-26}$

Patients in the total disclosure group were less willing to participate in clinical trials, according to their response to the questionnaire, but the difference in actual refusal rates was not significant. This implies that numbers in clinical trials may not be greatly reduced by patients refusing to enter the trials after disclosure of detailed information, but numbers could still be seriously affected if doctors, aware of patients' attitudes to participating in trials when full disclosure is required, are reluctant to include patients in such trials. For example, in a study of doctors participating in a large trial of the treatment of breast cancer this was one reason they gave for their reluctance to include patients in the study. ${ }^{10}$

Patients in the total disclosure group were initially more anxious than those who received an individual approach to consent. This finding raises the possibility that some patients may experience increased fears as a result of the disclosure of detailed information which a more sensitive and personal approach might have avoided. The desire by caring physicians to tailor the amount of information given to each patient in each clinical case is a compelling argument against a rigid procedure for obtaining informed consent. ${ }^{12}$ Nevertheless, some increased anxiety might be an unavoidable accompaniment for many patients faced with the decision of whether or not to participate in a clinical trial.

Concern about possible disruption of a positive doctor-patient 
relationship is a major factor in the reluctance of many doctors to seek fully informed consent from patients entering clinical trials ${ }^{9}$ or actually to participate in such trials. ${ }^{17}$ Our study did not show any difference for the two consent procedures in the doctor-patient relationship (as perceived by the patient), although because of the low power of the study an adverse effect cannot be ruled out.

In conclusion, our results clearly indicate some trade offs when patients are given all the relevant information compared with an individual approach to obtaining consent. Patients in the total disclosure group had a greater understanding of their treatment and of the research aspects of the trial but at the expense of increased anxiety. We hope that these results will stimulate similar controlled trials of consent practices at other hospitals, where the individual style of seeking consent may differ.

We are indebted to Stan Kaye and Margaret Brodie for their help in planning the study; to Cheryl Sutherland and Cheryl Swanson, who undertook the questionnaire interviews; to Richard Fox, David Hedley, Fred Kirsten, Graham Mann, and Ann Sullivan for their help with the consent interviews; and to Judy Hood for secretarial help. Dr Simes received support from an NH and MRC (Australia) Applied Health Sciences Fellowship. Statistical analysis, done at Dana Farber Cancer Institute, Boston, Massachusetts, USA, was supported by NCI grant number CA-23415.

\section{References}

1 Anonymous. Consent: how informed? [Editorial.] Lancet 1984;i: 1445-7.

2 Cancer Research Campaign Workıng Party in Breast Conservation. Informed consent: ethical, legal and medical implications for doctors and patients who participate in randomised clinical trials. Br Med f 1983;286:1117-21.

3 Anonymous. Research, consent, distress and truth. [Editorial.] f Med Ethics 1982;8:59-60.

4 Giertz G. Ethics of randomized clinical trials. I Med Ethics 1980;6:55-7.

5 Anonymous. Secret randomized trials. [Editorial.] Lancet 1982;ii:78-9.

6 Brewin TB. Consent to randomized treatment. Lancet 1982;ii:919-21.

7 Shafer A. The ethics of the randomized clinical trial. N Engl f Med 1982;307:719-24.

US Government Food and Drug Administration Code of Federal Regulations. Washington DC: US Government Printing Office, 1982 (DHEW publication): 191-3.

9 Ingelfinger FJ. Informed (but uneducated) consent. N Engl f Med 1972;287:465-6.

10 Taylor KM, Margolese RG, Soskolne CL. Physicians reasons for not entering patients in a randomized clinical trial of surgery for breast cancer. N Engl f Med 1984;310:1363-7.

11 Hellman S. Editorial: Randomized clinical trials and the doctor-patient relationship. Cancer Clinical Trials 1979:2:189-93.

12 Brewin TB. Truth, trust and paternalism. Lancet 1985 ;ii:490-2.

13 Kassirer JP. Adding insult to iniury. Usurping patients' prerogatives. $N$ Engl $\mathcal{f}$ Med 1983:308:898-901.

4 Kirby MD. Informed consent: what does it mean? f Med Ethics 1983;9:69-75.

14 Kirby MD. Informed consent: what does it mean? J Med Eth

15 Annas

16 Anonymous. On telling dying patients the truth. [Editorial.] f Med Ethics 1982;8:115-6.

17 Zelen $M$. The randomisation and stratification of patients to clinical trials. $\mathcal{J}$ Chronic Dis 1974;27:365-75

18 Spielberger CD, Gorsuch RL, Lushene RE. STAI annual for the state-trait anxiety inventory. Palo Alto: Consulting Psychologists Press, 1970.

19 Morrison DF. Multivariate statistical methods. New York: McGraw Hill, 1967;120, 223.

20 Mehta CR, Patel NR. A network algorithm for Fisher's exact test in rxc contingency tables. Journal of the American Statistical Association 1983;78:427-34.

21 Cassileth BR, Zupkis RV, Sutton-Smith K, March V. Informed consent-why are its goals imperfectly realized? $N$ Engl f Med 1980;302:896-900.

22 Epstein LC, Lasagna L. Obtaining informed consent. Form or substance? Arch Int Med 1969;123:682-8.

23 Morrow G, Gootnick J Schmale A A simple technique for increasing cancer patient's knowledge of informed consent to treatment. Cancer 1978;42:793-9.

24 Zelen M. A cew design for andomized clinical trials. N Englf Med 1979-300:1242-5.

25 Ellenberg SS. Randomization designs in comparative clinical trials. N Engl f Med 1984;310: 1404-8.

26 Gehan EA, Freireich EJ. Cancer clinical trials. A rational basis for use of historical controls. Semin Oncol 1981;8:430-6.

(Accepted 14 fuly 1986)

\title{
Decline in cardiovascular mortality in North Karelia and other parts of Finland
}

\author{
JAAKKO TUOMILEHTO, JEF GEBOERS, JUKKA T SALONEN, AULIKKI NISSINEN, \\ KARI KUULASMAA, PEKKA PUSKA
}

\begin{abstract}
The trends in mortality from ischaemic heart disease, cerebrovascular stroke, and all cardiovascular diseases were analysed for the province of North Karelia and for the rest of Finland. Linear trends in mortality were computed for the population aged 35 to 64 for the period from 1969 to 1982 , and changes in mortality between the three year means of 1969-71 and 1980-2 were calculated. In North Karelia, where a community based preventive programme has been carried out since 1972, the annual decline in mortality from ischaemic heart disease in men was on average $\mathbf{2 . 9 \%}$, whereas in the rest of Finland it was $2 \cdot 0 \%$. For
\end{abstract}

Department of Epidemiology, National Public Health Institute, 00280 Helsinki, Finland

JAAKKO TUOMILEHTO, MD, MPOLSC, professor

AULIKKI NISSINEN, MD, NT, assistant professor

KARI KUULASMAA, PHD, biostatistician

PEKKA PUSKA, MD, MPOLSC, professor

Department of Epidemiology, University of Leuven, Leuven, Belgium JEF GEBOERS, LICSC, biostatistician

Department of Community Health, University of Kuopio, Kuopio, Finland JUKKA T SALONEN, MD, MPH, professor

Correspondence to: Dr Tuomilehto. women the respective average annual declines in mortality were $4.9 \%$ and $3.0 \%$. The net decline from $1969-71$ to $1980-2$ in North Karelia was 100 deaths $/ 100000$ men. The annual mortality from all cardiovascular disease in men decreased by $2.9 \%$ in North Karelia and by $2.6 \%$ in the rest of Finland; in women the decreases were $6.0 \%$ and $5.0 \%$ a year, respectively. The net decline in North Karelia was 71 deaths/100000 men. The decline in mortality from all causes was also appreciable in both sexes in North Karelia, but it did not differ significantly from national trends.

\section{Introduction}

Awareness of the high incidence of cardiovascular disease in $\bar{O}$ Finland as a whole, and in North Karelia in particular, ${ }^{1.4}$ resulted in 0 a comprehensive, community based preventive programme to control cardiovascular disease: the North Karelia project. ${ }^{5}$ Its aim was to reduce mortality and morbidity from cardiovascular disease by reducing established risk factors, such as smoking, high serum cholesterol concentrations, and blood pressure, in the entire community. The favourable effects of this effort on these risk factors have been reported previously. ${ }^{5.8}$

Previous analyses have suggested that in the mid-1970s mortality from ischaemic heart disease started to decline faster in North Karelia than in the rest of Finland. ${ }^{9}$ In this report we estimate the trends in mortality from cardiovascular disease in North Karelia 